Saudi Journal of Oral and Dental Research

Abbreviated Key Title: Saudi J Oral Dent Res

ISSN 2518-1300 (Print) |ISSN 2518-1297 (Online)

Scholars Middle East Publishers, Dubai, United Arab Emirates

Journal homepage: https://saudijournals.com

\title{
Prevalence of Bruxism among Pregnant Patients of Lahore
}

\author{
Um-e-Farwa ${ }^{1}$, Saria Imtiaz ${ }^{2}$, Dania Fatima ${ }^{3}$, Aqsa Kiran ${ }^{4}$, Amina Tariq ${ }^{5 *}$
}

1,2,3 de, Montmorency College of Dentistry, Lahore Pakistan,

${ }^{4}$ University College of Medicine and Dentistry, University of Lahore Pakistan

${ }^{5}$ University College of Medicine and Dentistry, University of Lahore, Pakistan

DOI: $\underline{\text { 10.36348/sjodr.2020.v05i12.008 }}$ | Received: 09.11.2020 | Accepted: 22.12 .2020 | Published: 26.12 .2020

*Corresponding author: Amina Tariq

\section{Abstract}

The study aimed to explore the prevalence of bruxism in pregnant patients in public dental hospital of Lahore. This survey research was conducted in Public sector dental hospital by collecting data from 75 pregnant patients. Percentages were calculated to explore the prevalence of bruxism among pregnant patients. From data analysis, it was revealed that patients coming to the public dental hospital who had the history of bruxism before pregnancy were $50.7 \%$ whereas it rose to $67 \%$ who experience bruxism during pregnancy. In conclusion, this showed that pregnancy changes also elevate the bruxism experiences.

Key words: Pregnancy, Bruxism, Teeth grinding, Masticatory system.

Copyright $\odot$ 2020 The Author(s): This is an open-access article distributed under the terms of the Creative Commons Attribution 4.0 International License (CC BY-NC 4.0) which permits unrestricted use, distribution, and reproduction in any medium for non-commercial use provided the original author and source are credited.

\section{INTRODUCTION}

There are two types of masticatory system activities. One type is called functional type which includes mastication, phonation, whereas the second type is called parafunctional type which comprises of teeth clenching or grinding (known as bruxism). Parafunctional activity may include hyperactivity of muscle [1]. Bruxism is deliberated as pathological being if linked with unintentional mandibular movement (sliding). Clenching of teeth or teeth grinding up to the level of causing harm to the stomatognathic system is habitual practice in bruxism [2]. In temporomandibular joints, severe sliding motions, gross attrition on the edges of incisors as well as on the posterior teeth cusps, involuntary contraction of pterygoid muscles and teeth grinding sound during night sleep [3, 4].

Bruxism prevails in young individuals with an age ranges from 18 to 29 years was $13 \%$ [5]. In Brazil, this percentage of bruxism was found as $31.6 \%$ among undergraduate students [6]. Numerous studies have found a correlation between temporomandibular disorders and bruxism as they work in vice versa conditions in terms of triggers [7, 8]. In Pakistan, according to the Khan et al., 58.3\% patients who visited dental hospital in Peshawar reported bruxism [9].

No literature was cited related to the prevalence of bruxism among pregnant patients in Lahore. Thus, the study aimed to explore the prevalence of bruxism in pregnant patients in public dental hospital of Lahore.

\section{METHODOLOGY}

Research design: Descriptive Survey research Sampling technique: Convenient sampling Sample Size: 75 pregnant patients were taken as the sample of the study.

\section{Procedure}

After taking the permission from the Medical superintendent of the hospital, data was collected from the patients. Before collecting data from the pregnant patients, information about the research was briefed and then consent form was got signed from each participant. Questions were asked about whether they had ever experience night grinding or not as mentioned by other family members and whether they are experience night grinding or not during pregnancy as mentioned by other family members.

\section{DATA ANALYSIS}

Data was analyzed using SPSS version 20.0. Descriptive statistics (Percentages) were used to explore the prevalence of bruxism among pregnant patients.

\section{RESULTS}

As demographic variable, age of the pregnant females was taken to make two groups. Pregnant patients in group A had an age ranges from 18-27 which 


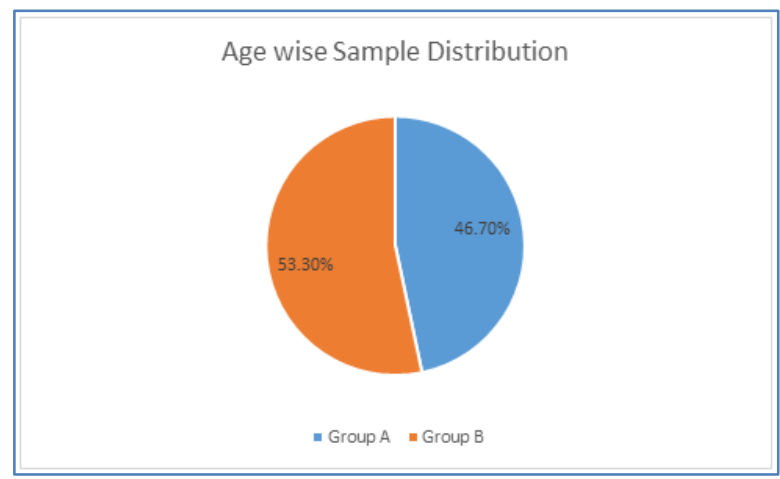

Fig-1: Age Wise Sample Details

From data analysis, it was revealed that patients coming to the public dental hospital who had the history of bruxism before pregnancy were $50.7 \%$ whereas it rose to $67 \%$ who experience bruxism during pregnancy.

Table-1: Percentage of bruxism experience before and during pregnancy

\begin{tabular}{|c|c|c|}
\hline & No & Yes \\
\hline History of Bruxism before pregnancy & $37(49.3 \%)$ & $38(50.7 \%)$ \\
\hline Bruxism experience During Pregnancy & $18(24 \%)$ & $57(76 \%)$ \\
\hline
\end{tabular}

\section{DISCUSSION}

This study aimed to explore the prevalence of bruxism in pregnant patients. The finding of this study explored that if a female has the history of bruxism before pregnancy, there is more change of experiencing bruxism during pregnancy. In this study, the pregnant patients with history of bruxism were $50.7 \%$ which raised to $76 \%$ who were experiencing bruxism during pregnancy. In a previous study conducted in Brazil showed that $31.6 \%$ students with age ranging from 1829 years [6] which was quite high among pregnant patients $76 \%$.

In Pakistan, according to the Khan et al. [9], $58.3 \%$ patients who visited dental hospital in Peshawar reported bruxism which was lower than the patients reported history of bruxism in present study $50.7 \%$ whereas among pregnant patients it was quite higher during pregnancy, i-e., $76 \%$.

In conclusion, this showed that pregnancy changes also elevate the bruxism experiences.

\section{REFERENCES}

1. Reddy, S. V., Kumar, M. P., Sravanthi, D., Mohsin, A. H. B., \& Anuhya, V. (2014). Bruxism: a literature review. Journal of international oral health: JIOH, 6(6), 105.

2. Murali, R. V., Rangarajan, P., \& Mounissamy, A. (2015). Bruxism: Conceptual discussion and review. Journal of pharmacy \& bioallied sciences, 7(Suppl 1), S265.
3. Ilovar, S., Zolger, D., Castrillon, E., Car, J., \& Huckvale, K. (2014). Biofeedback for treatment of awake and sleep bruxism in adults: systematic review protocol. Systematic reviews, 3(1), 1-9.

4. Kapusevska, B., Dereban, N., Popovska, M., Nikolovska, J., \& Popovska, L. (2013). Bruxism and TMD disorders of everyday dental clinical practice. Prilozi, 34(3), 105-11.

5. de la Hoz-Aizpurua, J. L., Díaz-Alonso, E., LaTouche-Arbizu, R., \& Mesa-Jiménez, J. (2011). Sleep bruxism. Conceptual review and update. Medicina Oral, Patologia Oral y Cirugia Bucal, 16(2), e231-8.

6. Soares, L. G., Costa, I. R., Brum Júnior, J. D. S., Cerqueira, W. S. B., Oliveira, E. S. D., Douglas de Oliveira, D. W., ... \& Flecha, O. D. (2017). Prevalence of bruxism in undergraduate students. CRANIO®, 35(5), 298-303.

7. Fernandes, G., Siqueira, J. T. T. D., Gonçalves, D. A. D. G., \& Camparis, C. M. (2014). Association between painful temporomandibular disorders, sleep bruxism and tinnitus. Brazilian oral research, 28(1), 1-7.

8. De Luca Canto, G., Singh, V., Bigal, M. E., Major, P. W., \& Flores- Mir, C. (2014). Association between tension- type headache and migraine with sleep bruxism: a systematic review. Headache: The Journal of Head and Face Pain, 54(9), 1460-1469.

9. Khan, M. A., Mansur, A., \& Amin, M. (2019). Prevalence of bruxism in undergraduate students, clinical staff and patients at Rehman College of dentistry. Pakistan Oral \& Dental Journal, 39(2), 218-221. 